\title{
Morbidity, life style and psychosocial situation in cancer survivors aged 60-69 years: results from The Nord-Trøndelag Health Study (The HUNT-II Study)
}

\author{
Ellen K Grov ${ }^{1,2^{*}}$, Sophie D Fosså ${ }^{1,3}$, Alv A Dahl ${ }^{1,3}$
}

\begin{abstract}
Background: Due to considerable health status differences in the elderly population, research limited to narrow age-spans might be an advantage. In this population-based controlled study we compare short-term ( $<5$ years) (STS) and long-term ( $\geq 5$ years) (LTS) cancer survivors and cancer-free controls aged 60-69 years from two Norwegian health registers; the Health Survey of North-Trøndelag County (HUNT-2 study) and the Cancer Registry of Norway (CRN). We examined possible factors associated with being cancer survivor.

Methods: Among 9,089 individuals aged 60-69 who participated in HUNT-2, 334 had been diagnosed with invasive primary cancer from 1 month to 42 years before HUNT-2 according to CRN and self-report. An overall random sample of controls without cancer five times larger than the sample of cases $(N=1,670)$ were drawn from the parent cohort.

Results: The cancer sample comprised 128 STS and 206 LTS. For most variables no significant differences were observed between LTS and STS. LTS were significantly more women, and cases with gynaecological cancer, with physical impairment and more thyroid diseases compared to STS. When comparing all the survivors with controls, the survivors showed significantly higher rate of pensioning, decreased self-rated health, more physical impairment and thyroid diseases, daily use of medication and psychotropics and higher level of anxiety and Framingham Risk score. Multivariate logistic regression analysis showed that increasing age, being female, physical impairment and thyroid diseases all were significantly associated with being survivor versus controls.
\end{abstract}

Conclusion: STS and LTS showed mostly similar situation. Compared to controls, the survivors reported somewhat poorer physical and mental health, but these differences were of doubtful clinical significance.

\section{Background}

In Norway $74 \%$ of those who are diagnosed with cancer, are 60 years or older [1], and the life expectancy is 78.2 years in men and 82.7 years in women [2]. Elderly Norwegians who get cancer, therefore often have a considerable lifetime ahead, and studies of their health and psychosocial situation are of substantial interest for prevention of morbidity and possible side effects of treatment. Cancer survivorship can be seen as an experience

\footnotetext{
* Correspondence: ellen.karine.grov@hibu.no

'Department of Clinical Cancer Research, The Norwegian Radium Hospital,

Oslo University Hospital, Oslo, Norway

Full list of author information is available at the end of the article
}

with different phases [3]. The concept may comprehend a stage of living with cancer with or without "treatment" or management [4], or concern patients with cancer "that is controlled with ongoing or periodic treatment" [5]. In most cases five years beyond diagnosis [6] or from end of primary treatment [7] are suggested as the border between short- and long-term survivorship.

Rowland \& Bellizzi (2008) [8] highlight the cancer survivors' situation as a melting pot with ingredients of more or less successful coping with bodily, social, mental, existential and economic aspects in life. Consequences of cancer diagnoses and treatment may persist over time with fatigue, digestive problems, sexual
Ciomed Central 
dysfunctions, body image changes, comorbidity like cardiovascular disease and osteoporosis, as well as changed attitudes to life as a whole. Several population-based studies of cancer patients have described their psychosocial situation and morbidity, but most of them cover large age intervals. Hewitt et al. reported findings from the American National Health Interview Study [9] comparing cancer patients aged 18 to 75 years to individuals without cancer. Their main findings, and thereby the core challenges in cancer survivors, are poorer health, more functional limitations, higher prevalence of comorbid medical diagnoses, and limitations in performing activities of daily life. However, an age span between 18 and 75 years makes it difficult to specify findings relevant to young, middle-aged or elderly survivors, as their situation and expectations vary considerably with the different phases of life [10]. Blank \& Bellizzi [11] studied prostate cancer survivors aged 47 to 88 years and found that increasing age was moderately associated with comorbidity. An optimally designed study includes stratification of some variables in order to create a homogenous sample. In our study we selected cancer survivors in the age span 60-69 for specifications related this age category, which in Norway represent the end of active work life for the majority of people. Alfano et al. (2007) [12] report on a sample of cancer survivors aged 29 to over 70 years without age stratification of the analyses. This sample will certainly allow for reflections about the influence of age related concerns when studying morbidity, psychosocial aspects and lifestyle.

Deimling et al. [13] studied older adult survivors (mean age 72.3 years, range $<60->75$ years) reporting that elderly cancer survivors were vulnerable for functional difficulties, and to comorbid health conditions, where pain was the most common symptom attributed to cancer or cancer treatment. Sweeney et al. [14] focused on elderly female cancer survivors, $57 \%$ of them older than 68 years (mean age 72 years, range 66-82 years), who carry a risk of confounding of age-related morbidity with the effects of cancer and its treatment. Several functional limitations were significantly more frequently reported among elderly female cancer survivors compared to controls without cancer. In a study among elderly cancer survivors, $\geq 65$ years, Grov et al. [15] showed significant associations between somatic comorbidity, lifestyle, and somatic symptoms.

In order to prevent morbidity and long-term effects after cancer and its treatment, health care personnel should be aware of cancer survivors' vulnerability for health problems, unfavorable life style, and psychosocial challenges. These are factors that we hypothesize to be associated with the survivors' age and time since diagnosis.
We hold the view that morbidity studies of cancer survivors should be restricted to defined age spans. Therefore, this study focused on cancer survivors aged between 60 and 69 years. This decade includes regular retirement (from 62 to 69 years of age in Norway), and increasing risk of somatic morbidity and symptomatology. In the decade from 60 to 69 years, the rate of cognitive impairment is low, and self-report is therefore a reliable mode of data collection. Lifestyle changes are still possible with the aim to decrease the risk for cardiovascular comorbidity and long-term health effects after cancer treatment $[16,17]$.

An ideal study would have a longitudinal design with follow-up for the selected groups of cancer survivors (60-69 years) to be continued for ten years (to the survivors reach the age of 70-79). The study should have no dropouts, and the treatment given to all cancer patients should be well documented, and all relevant variables for the study of morbidity, lifestyle and psychosocial situation must be covered. Norway has special opportunities in research on cancer survivors due to the unique person number allowing for linkage between high quality health-related registries. In this study, persons aged 60 to 69 years participating in the Health Survey of Nord-Trøndelag County 1995-97 (HUNT-2) were linked to the Cancer Registry of Norway (CRN).

Since the dataset from the HUNT-study covers many relevant variables about morbidity, psychosocial situation and lifestyle, we considered that our study could give valid information regarding several aspects concerning the situation of cancer survivors. All these variables are relevant for planning health care service for cancer survivors. Compared to other studies in the field, our study had the following advantages: internationally accepted schedules like the HADS, the Rosenberg instrument, and the Framingham Risk Index, in addition to a variety of somatic symptoms included by the gold standard of selfreport, and a valuable link to cancer specific register data by the Cancer Registry of Norway (CRN) which contributes with data on quite reliable cancer diagnoses.

The aim of the study was to examine morbidity, lifestyle and psychosocial situation in a sample of patients with invasive cancer compared to a random sample of controls without cancer. 1) We first compared cancer patients with primary diagnosis $<5$ years before HUNT-2 (Short Term Survivors, STS) to those who had their diagnosis $\geq 5$ years before HUNT-2 (Long Term Survivors, LTS). 2) We then compared the cancer survivors (SURV) with controls without cancer (controls). Our hypotheses were for 1) that no significant differences between shortand long-term survivorship would be demonstrated, and for 2) that SURV would show more morbidity, and similar lifestyle and psychological situation as controls. 


\section{Methods}

\section{Sampling}

The second Health Survey of Nord-Trøndelag County (HUNT-2) invited all inhabitants of the County aged 20 years and above to a health survey. The survey was done locally through the 24 municipalities of the County between August 1, 1995 and June 30, 1997. The personal invitation provided time and place for a simple physical examination, non-fasting blood sampling, and also included a questionnaire (Form 1), to be filled in and delivered at the examination. At the examination a second questionnaire (Form 2) was handed out to be returned by prepaid mail. Details of the HUNT-2 study are given elsewhere [18], (http://www.hunt.ntnu.no). Within the 60-69 years age group 10,611 individuals were invited to HUNT-2, and 9,089 (86\%) participated.

Report of all cancer cases occurring in Norway to the CRN has been mandatory by law since 1953, and the $\mathrm{CRN}$ is considered as a quite complete and reliable registry concerning cancer localization and invasiveness. Based on the person numbers an authorized linkage between HUNT-2 and the CRN, identified 428 participants (5\%) with at least one diagnosis of invasive cancer diagnosed $>1$ month before their HUNT-2 examination. Basal cell and squamous cell carcinomas (skin cancer) were excluded due to its superficial character not incorporated in our way of defining 'invasive cancer', which means more aggressive invasion into the tissue. From the 428 we excluded 71 participants found in the CRN but who did not self-report cancer, and 23 participants who had not filled in Form 2. This left us with a sample of 334 cancer patients (cases), among them 128 (38\%) had been diagnosed with cancer $<5$ years before HUNT2 (STS group) and $206(62 \%) \geq 5$ years before HUNT-2 (LTS group).

Among the 8,661 participants in the parent cohort not registered in the CRN, we excluded 56 who reported cancer but did not have a record in the Registry, and 609 participants who did not fill in Form 2. From the rest of 7,996 participants in the parent sample, we drew an overall random sample of five controls for each case, and these 1,670 participants represented the control group (NORM).

\section{Variables}

\section{Demographic variables}

Civil status was dichotomized into those married and those single, separated, divorced or widowed. Level of basic education was dichotomized into $<10$ years and $\geq 10$ years. The work situation was divided into those being in paid work or independent business versus those on age or disability pension. Economic problems last year were defined as reported problems paying bills during that time. Social network was assessed by having enough friends or not, and social activities were defined as being active in social clubs $\geq 1$ time/month or not.

\section{Lifestyle variables}

Daily smoker was registered for persons who reported daily consumption of cigarettes. Body Mass Index (BMI) was calculated. The level of physical activity was divided into "minimal" and "moderate or more" according to Thorsen et al. [19]. The "minimally active" category represents not sweaty/breathless activity $\geq 1$ hour per week, and either no or $<1$ hour per week of higher-level activity (sweaty/breathless). The "moderate or more" category is defined by higher-level activity $\geq 1$ hour per week. The Framingham Risk Index score was calculated for males and females according to algorithms of the Adult Treatment Panel [20], which includes weighted assessments of cholesterol, high density cholesterol, smoking and blood pressure, and indicates to what degree a person is at risk for developing coronary heart disease or sudden cardiac death within 10 years.

\section{Somatic morbidity variables}

Impairment was defined as caused by chronic disease, injury or somatic or mental morbidity leading to reduced activity of daily living, and divided into mainly physical or mental impairment. Self-rated health was rated to be "good" (very good/good) or "poor" (poor/ very poor). Somatic diseases were asked for by the question: "Has a doctor ever said that you had...?": myocardial infarction, angina pectoris, stroke, diabetes, thyroid disease (either hyperthyroidism, hypothyroidism, goiter or other thyroid diseases), osteoporosis, arthritis/ arthroses (rheumatoid arthritis, arthrosis or ankylosing spondylitis), and musculo-skeletal diseases (including fibromyalgia). A diagnosis of either myocardial infarction, angina pectoris, or stroke, qualified for a diagnosis of cardiovascular disease. Comorbid disease(s) were present if the patients had $\geq 1$ of these diseases. Somatic symptoms covered gastrointestinal ones (nausea, heartburn, diarrhea, or constipation) if they had caused "much bother last year", and headache defined as attacks during the last year. Muscular pain and stiffness affecting activities of daily living last month was rated as present or absent.

Regular use of medication last year concerned daily use of any medication, and regular use of antihypertensives, analgesics, and psychotropics (hypnotics, anxiolytics, and/or antidepressants) were registered. Daily use refers to daily consumption during the last 12 months.

\section{Mental distress variables}

Anxiety and depression were self-rated with The Hospital Anxiety and Depression Scale (HADS). The psychometric properties of the scale had been tested in HUNT-2 $[21,22]$. Scores on the anxiety and depression sub-scales ranged from 0 to 21 , respectively, and higher scores mean increased symptom load. HADS-defined caseness of 
anxiety and depression were identified by a cut-off $\geq 8$ on the subscale scores [21]. The correlation between the anxiety and depression subscales were Spearman's $r=0.62$. Internal consistency by Cronbach's coefficient $\alpha$ was 0.85 for the anxiety-subscale, and 0.78 for depression.

Rosenberg self-esteem score was assessed with four of the 10 items introduced by Rosenberg [23]. These items were self-rated on four-point Likert scales ranging from "strongly agree" to "strongly disagree" [24], and the score ranged from zero to 12 , with higher scores meaning better self-esteem. Internal consistency measured by Cronbach's coefficient $\alpha$ was 0.69 .

Sleeping problems were present if they regularly occurred for one or more nights a week. Alcohol problems were present in respondents who scored positively on one or more of the four CAGE items [25,26].

\section{Data from the Cancer Registry (CRN)}

For all cancer patients the following data were collected from the CNR: 1) date of first cancer and the interval to their HUNT-2 participation; 2) localization of cancer were categorized into six groups according to organ systems, where skin cancers were excluded.

\section{Statistical analysis}

Data were analyzed by SPSS-PC, version 15.0. Continuous variables were examined with t-tests, and categorical variables with $\chi^{2}$-tests. Non-parametric tests were applied in case of skewed distributions. Statistically significant group differences were examined for clinical significance by means of effect sizes (ESs) [27]. Clinical significance is the conclusion that a group difference has an effect of practical meaning to patients and health care providers. Even though a group difference is found to be statistically significant, this difference may not be clinically significant. For continuous variables we used Cohen's coefficient $\mathrm{d}$, and for $2 \times 2$ contingency tables the differences between arcsine transformed proportions and ES values $\geq 0.40$ were considered as clinically significant based on the recommendations of Cohen [28-30].

Internal consistencies of scales and subscales were examined by Cronbach's coefficient $\alpha$. A standard (unconditional) multivariate logistic regression analysis examined the associations between the dependent variable (cancer survivors or controls), and the selected independent variables showing significant associations in the bivariate analysis. Strength of association was expressed as odds ratio (OR) with 95\% confidence interval $(95 \% \mathrm{CI})$. The significance level was set at $\mathrm{p}<0.05$, and all tests were two-tailed.

\section{Ethics}

The HUNT-2 study was approved by The Norwegian Data Inspectorate and by The Regional Committee for
Medical Research Ethics, Health Mid-Norway. All participants in HUNT-2 gave written informed consent.

\section{Results}

\section{Characteristics of the cancer survivors}

No significant age difference was found between STS and LTS. The mean time from diagnosis of cancer to the HUNT-2 examination was 2.3 years (median 2.1) among STS and mean 13.8 (median 12.6) among LTS, which was to be expected considering the definitions of the STS and LTS. The time interval between diagnosis and HUNT-2 was significant longer in female cancer survivors, and they had lived a mean of 12 years (median 8.5) since their primary diagnosis. For male survivors the comparable mean was 7.5 years (median 5.0 ). Analyses on 5-year survival show that of the 334 participants in this study 78 have died of cancer, where 38 of them have survived less than 5 years (data until 2005).

The most common localizations of cancer were breast, gastrointestinal tract, and the group of other organ systems. STS contained significantly less gynaecological cancer $(E S=0.41)$ and more prostate cancer $(E S=0.62)$ than LTS, and both these findings showed clinical significance.

\section{Comparisons of STS and LTS}

There were significantly more females among LTS than STS (ES = 0.33), and therefore all analyses comprising morbidity and lifestyle variables are adjusted for sex. Concerning other socio-demographic, work, and social activity variables no significant differences were observed between LTS and STS (Table 1).

As to somatic variables LTS showed significantly more thyroid diseases $(E S=0.36)$ and more physical impairment $(E S=0.24)$ than STS, but no other somatic variables showed significant group differences (Table 2). Neither was any significant differences observed concerning daily use of any medication or regular use of analgesics, psychotropics or antihypertensive medication.

No significant differences concerning mental morbidity or lifestyle variables were observed between LTS and STS (Table 2).

\section{Comparisons between cancer survivors and controls}

Since only two variables among socio-demographic, somatic, mental and lifestyle ones showed significant differences (thyroid diseases and physical impairment), we found it allowable to analyze LTS and STS taken together as survivors versus controls.

The survivors was significantly older than the controls $(E S=0.24)$, and there were significantly more females among survivors $(E S=0.26)$. In the analyses of other variables we adjusted for age and sex. Only two significant differences among socio-demographic were 
Table 1 Demographic and clinical characteristics of short- and long-term cancer survivors

\begin{tabular}{|c|c|c|c|c|}
\hline Variables & $\begin{array}{c}\text { Short-term } \\
\text { survivors } \\
(\mathrm{N}=128)\end{array}$ & $\begin{array}{c}\text { Long-term } \\
\text { survivors } \\
(\mathrm{N}=206)\end{array}$ & $\mathrm{p}$-value & $\begin{array}{c}\text { Effect } \\
\text { Size }\end{array}$ \\
\hline Age, mean (SD) & $65.3(2.9)$ & $65.0(3.0)$ & 0.28 & \\
\hline \multicolumn{5}{|l|}{ Time since diagnosis (years) } \\
\hline Mean (SD) & $2.3(1.4)$ & $13.8(7.2)$ & $<0.001$ & 2.00 \\
\hline Median & 2.1 & 12.6 & & \\
\hline Range & $0.1-5.0$ & $5.1-42.2$ & & \\
\hline \multicolumn{5}{|l|}{ Localization of cancer, $N(\%)$} \\
\hline Respiratory tract & $5(4)$ & $11(5)$ & 0.79 & \\
\hline Gastrointestinal tract & $28(22)$ & $32(15)$ & 0.14 & \\
\hline Breast & $33(26)$ & $57(27)$ & 0.80 & \\
\hline Gynecological & $13(10)$ & $52(25)$ & 0.001 & 0.41 \\
\hline Prostate & $24(19)$ & $5(2)$ & $<0.001$ & 0.62 \\
\hline Other organ systems & $25(20)$ & $49(23)$ & 0.41 & \\
\hline Sex, $N(\%)$ & & & 0.002 & 0.33 \\
\hline Male & $57(44)$ & $58(28)$ & & \\
\hline Female & $71(56)$ & $148(72)$ & & \\
\hline Civil status, $N(\%)$ & & & $0.95^{*}$ & \\
\hline Married & $95(74)$ & $147(71)$ & & \\
\hline Single, separated, divorced, widowed & $33(26)$ & $59(29)$ & & \\
\hline Level of basic education, $N(\%)$ & & & $0.66^{*}$ & \\
\hline$<10$ years & $76(63)$ & $130(68)$ & & \\
\hline$\geq 10$ years & $45(37)$ & $61(32)$ & & \\
\hline \multicolumn{5}{|l|}{ Work status, N (\%) } \\
\hline Paid work, independent business & $37(29)$ & $51(25)$ & $0.71^{*}$ & \\
\hline Disability or age pension & $89(70)$ & $144(70)$ & $0.95^{*}$ & \\
\hline Economic problems last year, $N(\%)$ & $14(11)$ & $22(11)$ & $1.00^{*}$ & \\
\hline Have enough friends, $N$ (\%) & $106(82)$ & $161(78)$ & $0.06^{*}$ & \\
\hline Active in social clubs $\geq 1$ time/month, $N(\%)$ & $47(40)$ & $94(51)$ & $0.11^{*}$ & \\
\hline
\end{tabular}

*Adjusted for sex.

observed namely that survivors had a higher proportion on pensions $(E S=0.25)$ and a lower proportion with economic problems $(E S=0.17)$ than the controls (Table 3).

Significantly more survivors than controls reported poor self-rated health $(E S=0.26)$, physical impairment $(\mathrm{ES}=0.26)$ and thyroid diseases $(\mathrm{ES}=0.23)$ compared to controls (Table 4), but none of these differences showed clinical significance (Table 4).

The proportions of individuals that used daily medication $(\mathrm{ES}=0.16)$, analgesics, or psychotropics $(\mathrm{ES}=0.17)$ were all significantly higher among survivors compared to controls. However these differences did not reach clinical significance.

Survivors showed significantly higher level of anxiety $(E S=0.20)$ and more HADS-defined cases of anxiety $(E S=0.31)$ than controls. The other mental variables did not show any significant differences between the groups (Table 4).

No significant differences between the groups were observed for any of the lifestyle variables, except for The
Framingham Risk Index mean score which was significantly higher in survivors compared to controls (ES = 0.14 ). However, the proportions with a risk $>20 \%$ did not differ significantly between the groups.

The standard multivariate logistic regression analysis with 'survivors versus controls' as dependent variable showed that increasing age, female sex, lack of economic problems, physical impairment, and presence of thyroid diseases were significantly associated with the dependent variable (Table 5).

\section{Discussion}

This study of cancer survivors aged 60-69 years and a random sample of controls had two main findings: 1) Among LTS there were significantly more females, and more cases with gynecological cancer, physical impairment, thyroid diseases, but fewer cases with prostate cancer than among STS. Only the differences concerning cancer types reached clinical significance, however they represent 94/334 patients $(28 \%)$, which leaves limited reason to believe, that 
Table 2 Somatic and mental morbidity of short- and long-term cancer survivors

\begin{tabular}{|c|c|c|c|c|}
\hline Variables & $\begin{array}{c}\text { Short- } \\
\text { term } \\
\text { survivors } \\
(\mathrm{N}= \\
128)\end{array}$ & $\begin{array}{c}\text { Long- } \\
\text { term } \\
\text { survivors } \\
(\mathrm{N}= \\
206)\end{array}$ & $\begin{array}{c}\mathrm{p}- \\
\text { value* }\end{array}$ & $\begin{array}{l}\text { Effect } \\
\text { Size }\end{array}$ \\
\hline Self-rated health & & & 0.62 & \\
\hline Good health & $59(47)$ & $92(45)$ & & \\
\hline Poor health & $66(53)$ & $112(55)$ & & \\
\hline \multicolumn{5}{|l|}{ Functional impairment } \\
\hline Physical impairment & $16(13)$ & $45(22)$ & 0.04 & 0.24 \\
\hline Mental impairment & $8(6)$ & $15(7)$ & 0.89 & \\
\hline \multicolumn{5}{|l|}{ Somatic diseases } \\
\hline Infarction, angina or stroke & $18(14)$ & $26(13)$ & 0.96 & \\
\hline Diabetes & $5(4)$ & $9(4)$ & 0.82 & \\
\hline Thyroid diseases & $9(7)$ & $39(19)$ & 0.01 & 0.36 \\
\hline Osteoporosis & $3(2)$ & $14(7)$ & 0.16 & \\
\hline Arthritis, arthrosis & $31(24)$ & $49(24)$ & 0.62 & \\
\hline Musculo-skeletal diseases & $18(14)$ & $36(18)$ & 0.45 & \\
\hline$\geq 1$ comorbid disease $(\mathrm{s})$ & $57(45)$ & $112(54)$ & 0.12 & \\
\hline \multicolumn{5}{|l|}{ Significant somatic symptoms } \\
\hline \multicolumn{5}{|l|}{$\begin{array}{l}\text { Muscular pain and stiffness } \\
\text { affect- }\end{array}$} \\
\hline $\begin{array}{l}\text { ting daily activities last } \\
\text { month }\end{array}$ & $18(14)$ & $48(23)$ & 0.05 & \\
\hline $\begin{array}{l}\text { Gastrointestinal symptoms } \\
\text { last year }\end{array}$ & $11(9)$ & $16(8)$ & 0.82 & \\
\hline Headache last year & $24(19)$ & $52(25)$ & 0.35 & \\
\hline \multicolumn{5}{|l|}{$\begin{array}{l}\text { Regular use of medication last } \\
\text { year }\end{array}$} \\
\hline $\begin{array}{l}\text { Daily use of any } \\
\text { medication }\end{array}$ & $76(59)$ & $114(53)$ & 0.55 & \\
\hline Analgesics & $21(16)$ & $31(15)$ & 0.83 & \\
\hline Psychotropics & $25(19)$ & $43(21)$ & 0.99 & \\
\hline Antihypertensives & $25(20)$ & $50(24)$ & 0.33 & \\
\hline \multicolumn{5}{|l|}{ Mental variables } \\
\hline HADS-Anxiety, mean (SD) ${ }^{a}$ & $4.8(4.1)$ & $4.8(3.7)$ & 0.78 & \\
\hline $\begin{array}{l}\text { HADS-Depression, } \\
\text { mean (SD) a }\end{array}$ & $4.1(3.3)$ & $4.4(3.2)$ & 0.56 & \\
\hline $\begin{array}{l}\text { Self-esteem score, } \\
\text { mean (SD) }\end{array}$ & $7.9(2.1)$ & $7.7(2.2)$ & 0.54 & \\
\hline Sleeping problems, N (\%) & $30(25)$ & $59(32)$ & 0.33 & \\
\hline Alcohol problems, N (\%) & $8(6)$ & $17(8)$ & 0.15 & \\
\hline \multicolumn{5}{|l|}{ Lifestyle variables } \\
\hline BMI, mean (SD) & $27.6(3.8)$ & $27.6(4.8)$ & 0.70 & \\
\hline \multicolumn{5}{|l|}{ Physical activity, N (\%) } \\
\hline Minimal & $40(31)$ & $80(39)$ & 0.63 & \\
\hline Moderate or more & $88(69)$ & $126(61)$ & 0.48 & \\
\hline Daily smoker & $26(20)$ & $55(27)$ & 0.38 & \\
\hline \multicolumn{5}{|l|}{ Framingham risk score } \\
\hline $\begin{array}{l}\text { Framingham sum score, } \\
\text { mean (SD) }\end{array}$ & $16.1(2.8)$ & $16.6(3.0)$ & 0.15 & \\
\hline $\begin{array}{l}\text { Framingham risk >20\%, } \\
\text { N (\%) }\end{array}$ & $69(54)$ & $123(60)$ & 0.48 & \\
\hline
\end{tabular}

${ }^{*}$ Adjusted for sex ${ }^{\text {a }}$ Non-parametric test. types of treatment differed systematically or significantly between the groups of survivors. 2) A considerable number of significant differences were observed between cancer survivors and controls. The survivors were significantly older and had a higher proportion of females than controls. Among survivors a significant higher proportion were pensioned, had poorer self-rated health, physical impairment, thyroid diseases, daily use of medication and psychotropics, and HADS-defined anxiety disorders than controls. The mean scores on anxiety and Framingham Risk Index were also significantly higher among survivors than controls. None of these differences showed clinical significance, however. We conclude that survivors in the age group of 60-69 years are worse of in several respects compared to controls. However, the clinical consequences of these differences are in need of further investigation. In multivariate analysis having thyroid diseases was significantly and positively associated with being survivor, and such diseases were significantly more common among LTS than STS, so investigations of the thyroid and follow-up of such diseases seems worthwhile in the group of survivors.

Somewhat poorer self-rated health and more physical impairment in survivors than among controls are in line with the findings from the study by Hewitt et al. [9], where especially the subgroup $\geq 65$ years with a history of cancer reported significantly poorer health and more disability than age-matched controls without cancer. Our results support the study by Yabroff et al. [31] in which cancer survivors reported significantly poorer health compared to matched controls. Yabroff et al. also concluded with higher rate of pensioning and less work ability in survivors compared to controls. However, the comparison with that study might be biased due to their large age span $(<20-\geq 70$ years $)$. The problem regarding comparisons with studies using long age spans is also relevant in relation to other studies such as Hewitt et al. [9], Deimling et al. [13], and Blank \& Bellizzi [11].

Except for thyroid diseases, survivors did not have more somatic diseases or bothering somatic symptoms than controls. The thyroid findings might be related to the high proportion of breast cancer patients in the study since a clear association with thyroid diseases has been shown in such patients [32]. In multivariate analysis having thyroid diseases was significantly and positively associated with being survivor, and such diseases were significantly more common among LTS than STS, so investigations of the thyroid and follow-up of such diseases seem worthwhile in the group of survivors. Physical impairment was also significantly associated with survivor status in the multivariate analysis, but since we have no further details on this variable, evaluation and interventions cannot be suggested by us. 
Table 3 Demographic, work, social activity and health care consumption s of cancer survivors and controls

\begin{tabular}{|c|c|c|c|c|}
\hline Variables & $\begin{array}{l}\text { Survivors } \\
(\mathrm{N}=334)\end{array}$ & $\begin{array}{c}\text { Controls } \\
(\mathrm{N}=1,670)\end{array}$ & p-value & $\begin{array}{l}\text { Effect } \\
\text { size }\end{array}$ \\
\hline \multirow[t]{2}{*}{ Age at survey, mean (SD) } & $65.1(2.9)$ & $64.4(2.9)$ & $<0.001$ & 0.24 \\
\hline & $N(\%)$ & $N(\%)$ & & \\
\hline Sex & & & $<0.001$ & 0.26 \\
\hline Males & $115(34)$ & $792(47)$ & & \\
\hline Females & $219(66)$ & $878(53)$ & & \\
\hline Civil status & & & $<0.43^{*}$ & \\
\hline Married & $242(73)$ & $1,280(77)$ & & \\
\hline Single, separated, divorced, widow(er) & $92(27)$ & $387(23)$ & & \\
\hline Level of basic education & & & $0.77^{*}$ & \\
\hline$<10$ years & $206(66)$ & $953(62)$ & & \\
\hline$\geq 10$ years & $106(34)$ & $583(38)$ & & \\
\hline \multicolumn{5}{|l|}{ Work situation } \\
\hline Paid work, independent business & $88(26)$ & $593(36)$ & $0.30^{*}$ & \\
\hline Disability or age pension & $233(70)$ & $961(58)$ & $0.006^{*}$ & 0.25 \\
\hline Economic problems last year & $36(12)$ & $288(18)$ & $0.02^{*}$ & 0.17 \\
\hline Have enough friends & $267(87)$ & $1,396(87)$ & $0.75^{*}$ & \\
\hline Active in social clubs $\geq 1$ time/month & $141(46)$ & 761 (48) & $0.33^{*}$ & \\
\hline
\end{tabular}

* Adjusted for age and sex.

No significant differences were found between survivors and controls for cardiovascular diseases or antihypertensive medication. We had expected such difference, or at least significant differences between the groups for Framingham Risk Index. The latter was found for the mean scores, but the ES $=0.14$ indicated doubtful clinical relevance, particularly since no significant difference was found for the high risk $(>20 \%)$ cases. Previous studies have reported increased heart-related comorbidity in cancer survivors, but differences in sampling can explain the divergent findings $[13,16,17,33]$.

We observed no significant differences between survivors and controls on variables that are relevant for lifestyle interventions. The group in need of such interventions must therefore be defined by other variables than survivor status.

As observed in the study of Mehnert \& Koch [34], our findings also support the lower level of self-rated health in cancer survivors compared to controls. However, Mehnert \& Koch found a significantly higher level of depression in elderly breast cancer survivors compared to controls, while that was not the case in our study (mean 4.4, SD 3.5, and mean 4.1, SD 3.3, $\mathrm{p}=0.26$ for female survivors and controls, respectively). In contrast, we observed a higher level of anxiety in survivors compared to controls, however not to clinically significant degree. Since the HADS anxiety and depression subscales are highly correlated, the two studies have in common a higher level of mental distress in survivors compared to controls.

To our knowledge there are hardly any studies that compare LTS and STS on the variables examined in this study. Our hypothesis of significant differences between the groups was hardly confirmed. However, the hypothesis of more morbidity among survivors compared to controls was confirmed. Health care personnel should be aware of health problems in cancer survivors by highlighting assessments of their physical and mental health. Poor physical health and mental distress might have implications for the way cancer survivors cope with e.g. performance of activity of daily living, their use of medication, and their social capability.

The few significant differences observed could be due to chance since we did a considerable number of comparisons. If we apply Bonferroni's correction for multiple comparisons we get a p-value of $0.002(0.05 /$ 32 ), and no significant differences emerge. Few significant differences between LTS and STS could reflect that survivorship is a relatively stable state, but not necessarily without problems. As with other chronic diseases cancer survivors have to cope with challenges coming up now and then, and our findings indicate that cancer survivors find ways to deal with consequences of cancer treatment and side effects during the survivorship trajectory. We find the lack of difference between STS and LTS in a mixed sample of cancer survivors of considerable interest, and this result should be focus for more studies.

The strength of this study is the data collection combining data from a large health survey with a high quality cancer registry. Due to this combination, we also had opportunity to draw at random a control group from the same parent population, which is an advantage 
Table 4 Somatic and mental morbidity of cancer survivors and controls

\begin{tabular}{|c|c|c|c|c|}
\hline Variables & $\begin{array}{c}\text { Survivors } \\
(\mathrm{N}= \\
334)\end{array}$ & $\begin{array}{c}\text { Controls } \\
(N= \\
1,670)\end{array}$ & $\begin{array}{c}\mathrm{p}- \\
\text { value }\end{array}$ & $\begin{array}{c}\text { Effect } \\
\text { size }\end{array}$ \\
\hline Self-rated health & & & $<0.001^{*}$ & 0.26 \\
\hline Good health & $151(46)$ & $971(59)$ & & \\
\hline Poor health & $178(54)$ & $687(41)$ & & \\
\hline \multicolumn{5}{|l|}{ Functional impairment } \\
\hline Physical impairment & $76(23)$ & $230(13)$ & $<0.001^{*}$ & 0.26 \\
\hline Mental impairment & $14(4)$ & $62(4)$ & $0.62^{*}$ & \\
\hline \multicolumn{5}{|l|}{ Somatic diseases } \\
\hline Infarction, angina or stroke & $44(13)$ & $223(13)$ & $0.85^{*}$ & \\
\hline Diabetes & $14(4)$ & $73(4)$ & $0.83^{*}$ & \\
\hline Thyroid diseases & $48(14)$ & $121(7)$ & $0.001^{*}$ & 0.23 \\
\hline Osteoporosis & $17(5)$ & $65(4)$ & $0.84^{*}$ & \\
\hline Arthritis, arthrosis & $80(24)$ & $408(24)$ & $0.34^{*}$ & \\
\hline Musculo-skeletal diseases & $54(16)$ & $207(12)$ & $0.07^{*}$ & \\
\hline$\geq 1$ comorbid disease(s) & $169(51)$ & $809(48)$ & $0.99^{*}$ & \\
\hline \multicolumn{5}{|l|}{ Significant somatic symptoms } \\
\hline \multicolumn{5}{|l|}{$\begin{array}{l}\text { Muscular pain and stiffness } \\
\text { affecting }\end{array}$} \\
\hline $\begin{array}{l}\text { activities of daily living last } \\
\text { month }\end{array}$ & $66(20)$ & $322(19)$ & $0.70^{*}$ & \\
\hline $\begin{array}{l}\text { Gastrointestinal symptoms } \\
\text { last year }\end{array}$ & $36(11)$ & $165(10)$ & $0.82^{*}$ & \\
\hline Headache last year & $76(23)$ & $428(26)$ & $0.19^{*}$ & \\
\hline \multicolumn{5}{|l|}{$\begin{array}{l}\text { Regular use of medication last } \\
\text { year }\end{array}$} \\
\hline $\begin{array}{l}\text { Daily use of any } \\
\text { medication }\end{array}$ & $190(57)$ & $822(49)$ & $0.01^{*}$ & 0.16 \\
\hline Analgesics & $45(14)$ & $179(11)$ & $0.15^{*}$ & \\
\hline Psychotropics & $56(17)$ & $187(11)$ & $0.02^{*}$ & 0.17 \\
\hline Antihypertensives & $75(23)$ & $361(22)$ & $0.98^{*}$ & \\
\hline \multicolumn{5}{|l|}{ Mental variables } \\
\hline HADS-Anxiety, mean (SD) ${ }^{\mathrm{a}}$ & $4.8(3.8)$ & $4.0(3.4)$ & $0.001^{*}$ & 0.20 \\
\hline HADS-Anxiety caseness, N (\%) & $77(25)$ & $208(13)$ & $<0.001^{*}$ & 0.31 \\
\hline HADS-Depression, mean (SD) ${ }^{\text {a }}$ & $4.2(3.3)$ & $4.1(3.2)$ & $0.41^{*}$ & \\
\hline $\begin{array}{l}\text { HADS-Depression caseness, N } \\
(\%)\end{array}$ & $47(15)$ & $230(14)$ & $0.73^{*}$ & \\
\hline Self-esteem score, mean (SD) & $5.6(1.9)$ & $5.7(1.6)$ & $0.39^{*}$ & \\
\hline Sleeping problems, N (\%) & $89(29)$ & $385(24)$ & $0.35^{*}$ & \\
\hline Alcohol problems, N (\%) & $25(8)$ & $147(8)$ & $0.57^{*}$ & \\
\hline \multicolumn{5}{|l|}{ Lifestyle variables } \\
\hline BMl, mean (SD) & $27.6(4.5)$ & $27.4(4.2)$ & $0.84^{*}$ & \\
\hline Physical activity, N (\%) & & & $0.42^{*}$ & \\
\hline Minimal & $86(31)$ & $475(34)$ & & \\
\hline Moderate or more & $188(69)$ & $930(66)$ & & \\
\hline Daily smoker & $64(23)$ & $308(22)$ & $0.49^{*}$ & \\
\hline \multicolumn{5}{|l|}{ Framingham risk score } \\
\hline $\begin{array}{l}\text { Framingham sum score, } \\
\text { mean (SD) }\end{array}$ & $16.4(2.9)$ & $16.0(2.9)$ & 0.01 & 0.14 \\
\hline $\begin{array}{l}\text { Framingham risk }>20 \%, N \\
(\%)\end{array}$ & $198(58)$ & $867(52)$ & 0.12 & \\
\hline
\end{tabular}

* Adjusted for age and sex a Non-parametric test.
Table 5 Multivariate logistic regression analysis with cancer survivors $(N=334)$ versus controls $(N=1,670)$ as dependent variable

\begin{tabular}{lccc}
\hline Independent variables & OR & $\mathbf{9 5 \%} \mathbf{C l}$ & $\boldsymbol{P}$ \\
\hline Age & 1.09 & $1.03-1.15$ & 0.003 \\
Female (male = reference) & 1.57 & $1.12-2.20$ & 0.009 \\
Pensioned (not pensioned = reference) & 1.28 & $0.92-1.37$ & 0.14 \\
Economic problems last year & 0.54 & $0.36-0.80$ & 0.002 \\
Poor self-rated health (good = reference) & 1.27 & $0.95-1.71$ & 0.11 \\
Physical impairment present & 1.66 & $1.17-2.37$ & 0.005 \\
Thyroid diseases & 2.05 & $1.39-3.03$ & $<0.001$ \\
Daily use of psychotropics & 1.29 & $0.89-1.88$ & 0.18 \\
HADS Anxiety & 1.03 & $0.99-1.07$ & 0.14 \\
Framingham risk score & 0.95 & $0.89-1.00$ & 0.07 \\
\hline
\end{tabular}

for comparison. Population-based studies like HUNT-2 provide the opportunity to study a short age span of cancer survivors with a sufficient sample size. The use of internationally accepted schedules like the HADS, the Rosenberg instrument, and the Framingham Risk Index is an additional strength.

On the other hand, some limitations have to be considered when interpreting the results from this study. One is the large time of survivorship studied ranging from $0.1-42.2$ years. Fourteen per cent of those aged 60-69 years did not participate in HUNT-2. Among the 1,522 non-responders in the age group 60-69, 225 (14\%) had invasive cancer, while in the participant group $(9,089) 334(4 \%)$ had invasive cancer. These findings represent a source of systematic bias, and we suggest that one explanation is that they did not want to participate in the survey due to health problems. Therefore we cannot exclude a selection bias concerning the cancer survivors included compared to the survivors in the population. Additionally, more somatic symptoms might be present for the respondents, but they were not available for assessment in HUNT-2.

Our study had a cross sectional design which gives a snapshot of the cancer survivors' situation without opportunities to identify causal connection. We do not have any information concerning the non-responders to HUNT-2. The variables selected for the HUNT-study did not cover all variables relevant for the study of cancer survivors (e.g. pain was not covered). The Cancer Registry of Norway (CRN) does not have valid data on cancer treatment, which would have been highly relevant information. The survey was sampled some years ago. However, we cannot see that this delay influences the aims and results of this study. The cases have been divided into two subgroups under the same conditions related treatment and follow-up. Even if we take into account that new treatment modalities have emerged from the sampling of this study, the pattern of problems 
and challenges for short- and long-term survivors highlighted in our study still seem appropriate.

\section{Conclusion}

In this controlled population-based study of cancer survivors age 60-69 years, we observed few significant differences between LTS and STS. In accordance with other studies of elderly cancer survivors, we found significant differences between survivors and controls drawn at random within psychosocial, morbidity and lifestyle variables. However, none of these differences reached clinical significance. Anyway, health care personnel are recommended to identify individuals with health problems like thyroid disease among the cancer survivors, and to assess their physical and mental health in order to identify physical diseases and mental distress.

\section{Acknowledgements}

Ellen Karine Grov, MNSc, PhD received a postdoctoral research career grant given by Health South-East Regional Health Trust. The Nord-Trøndelag Health Study (The HUNT Study) is collaboration between HUNT Research Centre, Faculty of Medicine, Norwegian University of Science and Technology (NTNU, Verdal), Norwegian Institute of Public Health, and NordTrøndelag County Council.

\section{Author details}

'Department of Clinical Cancer Research, The Norwegian Radium Hospital, Oslo University Hospital, Oslo, Norway. ${ }^{2}$ Buskerud University College, Faculty of Health, Drammen, Norway. ${ }^{3}$ Faculty Division, The Norwegian Radium Hospital, University of Oslo, Oslo, Norway.

\section{Authors' contributions}

EKG, SDF \& AAD were responsible for the study conception and design. EKG, SDF \& AAD performed the data analysis. EKG, SDF \& AAD drafted the manuscript. EKG, SDF \& AAD made critical revisions to the paper for important intellectual content. EKG \& AAD provided statistical expertise, and EKG obtained funding. AAD \& SDF supervised the study. All authors read and approved the final manuscript.

\section{Conflict of interests statement}

The authors declare that they have no competing interests.

Received: 30 November 2009 Accepted: 26 January 2011

Published: 26 January 2011

\section{References}

1. Cancer Registry of Norway: Cancer in Norway 2008, Cancer incidence, mortality, survival, and plevalence in Norway. Cancer Registry of Norway Institute of Population-based Cancer Research; 2009, 1-64.

2. Statistics Norway 2008. [http://www.ssb.no]

3. Mullan F: Seasons of survival: reflections of a physician with cancer. $N$ Engl J Med 1985, 313:270-273.

4. Feuerstein M: Defining cancer survivorship. J Cancer Surviv 2007, 1:5-7.

5. Hewitt M, Greenfield S, Stovall E, Committee on Cancer Survivorship: Improving Care and Quality of Life loMaNRC: From Cancer Patient to Cancer Survivor. Lost in Transistion. 1 edition. The National Academies; 2005.

6. Aziz NM, Rowland $\mathrm{JH}$ : Trends and advances in cancer survivorship research: challenge and opportunity. Semin Radiat Oncol 2003, 13:248-266.

7. Fong $Y$, Gonen M, Rubin D, Radzyner M, Brennan MF: Long-term survival is superior after resection for cancer in high-volume centers. Ann Surg 2005, 242:540-544

8. Rowland $\mathrm{JH}$, Bellizzi KM: Cancer survivors and survivorship research: a reflection on today's successes and tomorrow's challenges. Hematol Oncol Clin North Am 2008, 22:181-200.
9. Hewitt M, Rowland JH, Yancik R: Cancer survivors in the United States: age, health, and disability. J Gerontol A Biol Sci Med Sci 2003, 58:82-91.

10. Rolland J: Cancer and the Family: An Integrative Model. Cancer Supp/ 2005, 104:2584-2595

11. Blank TO, Bellizzi KM: A gerontologic perspective on cancer and aging Cancer 2008, 112:2569-2576.

12. Alfano CM, Smith AW, Irwin ML, Bowen DJ, Sorensen B, Reeve BB, et al: Physical activity, long-term symptoms, and physical health-related quality of life among breast cancer survivors: a prospective analysis. J Cancer Surviv 2007, 1:116-128.

13. Deimling GT, Sterns S, Bowman KF, Kahana B: The health of older-adult, long-term cancer survivors. Cancer Nurs 2005, 28:415-424.

14. Sweeney C, Schmitz KH, Lazovich D, Virnig BA, Wallace RB, Folsom AR: Functional limitations in elderly female cancer survivors. $J$ Natl Cancer Inst 2006, 98:521-529.

15. Grov EK, Fossa SD, Dahl AA: Is somatic comorbidity associated with more somatic symptoms, mental distress, or unhealthy lifestyle in elderly cancer survivors? J Cancer Surviv 2009, 3:109-116.

16. Demark-Wahnefried W, Pinto BM, Gritz ER: Promoting health and physical function among cancer survivors: potential for prevention and questions that remain. J Clin Oncol 2006, 24:5125-5131.

17. Blanchard CM, Courneya KS, Stein K: Cancer survivors' adherence to lifestyle behavior recommendations and associations with health-related quality of life: results from the American Cancer Society's SCS-II. J Clin Oncol 2008, 26:2198-2204.

18. Holmen J, Midthjell $K$, Krüger $\varnothing$, Langhammer A, Holmen TL, Bratberg GH, et al: The Nord-Trøndelag Health Study 1995-97 (HUNT 2): Objectives, contents, methods and participation. Norsk Epidemiologi 2003, 13:19-32.

19. Thorsen L, Nystad W, Dahl O, Klepp O, Bremnes RM, Wist E, et al: The level of physical activity in long-term survivors of testicular cancer. Eur J Cancer 2003, 39:1216-1221.

20. Expert Panel III on Detection, Evaluation and Treatment of High Blood Cholesterol in Adults, Adult Treatment Panel III. Executive Summary of the Third Report of the National Cholesterol Education Program (NCEP) 2001 285:2486-2497.

21. Bjelland I, Dahl AA, Haug TT, Neckelmann D: The validity of the Hospital Anxiety and Depression Scale. An updated literature review. J Psychosom Res 2002, 52:69-77.

22. Mykletun A, Stordal E, Dahl AA: Hospital Anxiety and Depression (HAD) scale: factor structure, item analyses and internal consistency in a large population. Br J Psychiatry 2001, 179:540-544.

23. Rosenberg M: Society and the Adolscent Self-Image Princeton, Princeton University Press; 1965.

24. Tambs K: Moderate effects of hearing loss on mental health and subjective well-being: results from the Nord-Trondelag Hearing Loss Study. Psychosom Med 2004, 66:776-782.

25. Ewing JA: Detecting alcoholism. The CAGE questionnaire. JAMA 1984, 252:1905-1907.

26. Maly RC: Early recognition of chemical dependence. Prim Care 1993 20:33-50.

27. Nakagawa S, Cuthill IC: Effect size, confidence interval and statistical significance: a practical guide for biologists. Biol Rev Camb Philos Soc 2007, 82:591-605.

28. Cohen J: Statistical Power Analysis for the Behavioral Sciences. 2 edition Lawrence Erlbaum Associates, Inc., Publishers, New Jersey; 1988.

29. Lipsey MW, Wilson DB: Practical meta-analysis Thousand Oakes, CA: SAGE; 2001

30. Sloan JA, Vargas-Chanes D, Kamath CC, Sargent DJ, Novotny P, Atherton P, et al: Detecting worms, ducks, and elephants: A simple approach for defining clinically relevent effects in quality-of-life measures. Journal of Cancer Integrative Medicine 2003, 1:41-47.

31. Yabroff KR, Lawrence WF, Clauser S, Davis WW, Brown ML: Burden of illness in cancer survivors: findings from a population-based national sample. J Natl Cancer Inst 2004, 96:1322-1330.

32. Reinertsen $K$, Cvancarova M, Wist E, Bjøro T, Dahl A, Danielsen T, et al: Thyroid function in women after multimodal treatment for breast cancer stage ii/iii: comparison with controls from a population sample. Int J Rad Oncol Biol Phys 2008.

33. Anderson B, Sawyer DB: Predicting and preventing the cardiotoxicity of cancer therapy. Expert Rev Cardiovasc Ther 2008, 6:1023-1033. 
34. Mehnert A, Koch U: Psychological comorbidity and health-related quality of life and its association with awareness, utilization, and need for psychosocial support in a cancer register-based sample of long-term breast cancer survivors. J Psychosom Res 2008, 64:383-391.

\section{Pre-publication history}

The pre-publication history for this paper can be accessed here: http://www.biomedcentral.com/1471-2407/11/34/prepub

doi:10.1186/1471-2407-11-34

Cite this article as: Grov et al:: Morbidity, life style and psychosocial situation in cancer survivors aged 60-69 years: results from The NordTrøndelag Health Study (The HUNT-II Study). BMC Cancer 2011 11:34.

Submit your next manuscript to BioMed Central and take full advantage of:

- Convenient online submission

- Thorough peer review

- No space constraints or color figure charges

- Immediate publication on acceptance

- Inclusion in PubMed, CAS, Scopus and Google Scholar

- Research which is freely available for redistribution

Submit your manuscript at www.biomedcentral.com/submit
C Biomed Central 